\title{
A novel fluid-structure interaction model for lubricating gaps of piston machines
}

\author{
M. Pelosi \& M. Ivantysynova \\ Department of Agricultural and Biological Engineering \\ and School of Mechanical Engineering, Purdue University, USA
}

\begin{abstract}
The lubricating gaps between movable parts in piston machines represent the main source of power loss. A deep understanding of the complex physical phenomena characterizing the complex fluid-structure interaction is crucial for improving existing design and designing new more efficient machines. The lubricating gap in these machines has to fulfill a sealing and bearing function. Therefore the prediction of the gap flow, the load carrying ability and the energy dissipation is necessary. This paper discusses the different physical phenomena and presents a new fluid-structure interaction model for the piston/cylinder gap of axial piston machines. The model considers the squeeze film effect due to the micro-motion of the piston and simultaneously the change of fluid film thickness due to the deformation of parts caused by the fluid pressure field. In addition the fluid flow is considered as non-isothermal, which requires the coupling of a heat transfer model to predict the surface temperatures as boundary conditions for the non-isothermal fluid film model. The novelty of the developed fully coupled fluid-structure interaction model is the integration of a finite element solver in the dynamic non-isothermal fluid flow model. This allows for the first time to solve the elastohydrodynamic lubrication problem in complex changing load conditions, considering the impact of thermal effects. Simulation results of the piston/cylinder interface will be compared with pressure field and temperature measurements, obtained on a special test-rig.
\end{abstract}

Keywords: axial piston machines, hydraulic pumps and motors, lubricating gaps, thermoelastohydrodynamic lubrication, piston-cylinder interface. 


\section{Introduction}

Sealing and bearing gaps are one of the essential design elements for axial piston machines. A significant reduction in energy dissipation and an improvement in efficiency and power density can be reached, optimizing the gaps geometry. A sufficient load carrying ability of the lubricating film can be achieved; avoiding metal to metal contact, reaching full film hydrodynamic lubrication and drastically reducing the energy dissipation. Unlike other tribological contacts, the gaps of axial piston machines fulfill simultaneously a bearing and sealing function under extreme oscillating loads, making the optimization of gap geometry a very challenging task. Besides the main movement (in the case of the piston its axial movement and piston spin motion), the piston, slipper and cylinder block also perform a micro movement, changing the film thickness and generating an additional squeeze film effect.

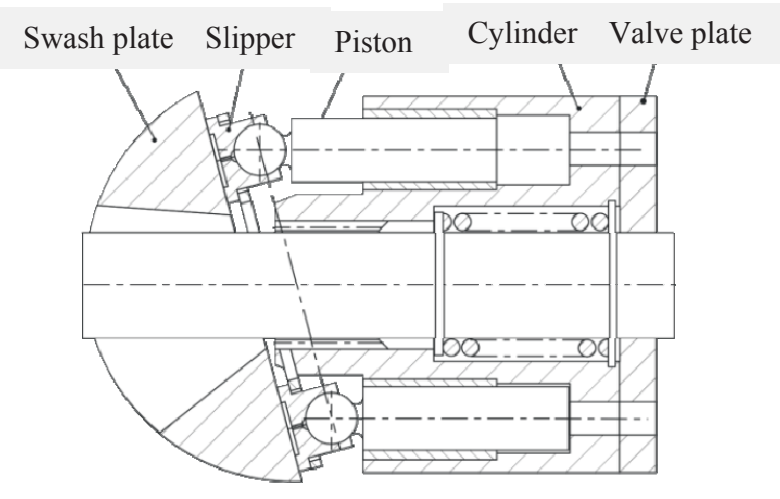

Figure 1: Lubricating gaps in an axial piston machine.

The Reynolds numbers in the lubricating gap are typically very low and therefore laminar flow conditions are always assumed. Several physical phenomena are taking place simultaneously inside the gaps, influencing the fluid flow conditions over one machine shaft revolution. In particular, the surface deformation of machine parts due to high operating pressure and even higher local pressure peaks in the lubricating gaps are usually in the range of some micro-meters. The local surface deformation due to the pressure field in the gap leads to a modification of the film thickness, which is defined as elastohydrodynamic effect. Furthermore, the energy dissipation generated due to viscous friction changes the oil viscosity and load carrying ability. Therefore, local viscosity change has to be considered based on the local temperature distribution. Many researchers investigated the behavior of lubricating gaps in axial piston machines, as described in [1-4], but none of the models developed considered the complex coupling of several physical effects. This paper presents a new model for an accurate prediction of fluid film thickness between piston/cylinder, considering surface elastic deformation coupled with thermal prediction of rigid body surface temperatures. The non-isothermal fluid flow 
conditions inside the piston/cylinder gap are solved using a finite volume discretization for both the Reynolds and the energy equations. The determination of surface elastic deformation is based on an advanced finite element model tool for both the piston and cylinder rigid bodies. The thermal problem is solved using a finite volume model for the piston/cylinder assembly, which, based on the heat transfer conditions, calculates the rigid body surface temperatures, used as a boundary for non-isothermal gap flow calculations.

\section{Piston/cylinder interface fully-coupled fluid-structure and thermal multi-body dynamics model}

The elastohydrodynamic non-isothermal gap flow in the region between piston and cylinder can be described using two main equations: the Reynolds equation and the energy equation. In particular, the Reynolds equation, eqn. (1), allows determination of the pressure distribution in the fluid inside the gap and for the first time in this kind of lubricating gap, a compressible form of the Reynolds equation is implemented.

$$
\frac{\partial}{\partial \hat{x}}\left(\frac{\rho h^{3}}{\mu} \frac{\partial p}{\partial \hat{x}}\right)+\frac{\partial}{\partial \hat{y}}\left(\frac{\rho h^{3}}{\mu} \frac{\partial p}{\partial \hat{y}}\right)=6\left(v_{\hat{x}} \frac{\partial \rho h}{\partial \hat{x}}+v_{\hat{y}} \frac{\partial \rho h}{\partial \hat{y}}+2 \rho \frac{\partial h}{\partial t}\right)
$$

where $\hat{x}$ and $\hat{y}$, eqn. (2), represent the gap circumference and the gap length in an unwrapped Cartesian coordinate system, under the assumption that the gap clearance is small compared to the piston radius $R_{K}$.

$$
\hat{x}=\phi_{\mathrm{K}} R_{\mathrm{K}} \text { and } \hat{y}=z_{\mathrm{K}}
$$

Due to the large oscillating external force over one shaft revolution, the piston moves in the cylinder and spins about its own axis at varying inclined positions.
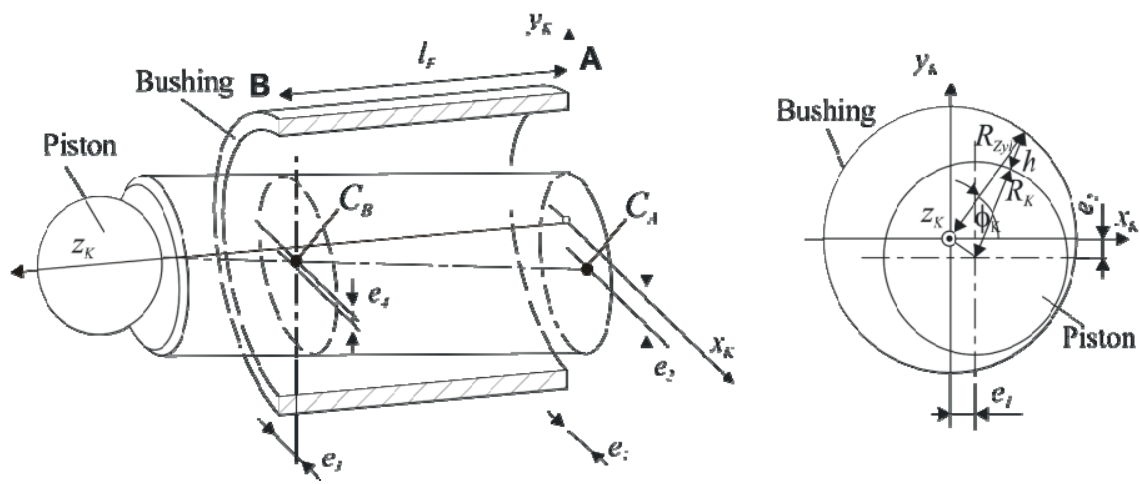

Figure 2: $\quad$ Piston/cylinder eccentricity and gap height definition.

This radial movement, which is in a range of only some microns, is defined as micro motion and contributes to the hydrodynamic pressure generation in the gap. In the Reynolds equation one of the most important parameter is the film thickness $h$ and its derivations. Fig. 2 shows the main parameters defining 
piston/cylinder film thickness. The local film thickness, eqn. (3), is calculated adding the contribution of the surface elastic deformation $\Delta h$ (fluid-structure interaction problem) to the film thickness $h$, function of the micro and macro motion of the piston:

$$
h\left(z_{\mathrm{K}}, \phi_{\mathrm{K}}\right)=\sqrt{\left(R_{\mathrm{Z}} \cos \phi_{\mathrm{K}}-x_{m}\left(z_{K}\right)\right)^{2}+\left(R_{\mathrm{Z}} \sin \phi_{\mathrm{K}}-y_{m}\left(z_{K}\right)\right)^{2}}-R_{\mathrm{K}}+\Delta h
$$

With:

$$
x_{m}\left(z_{K}\right)=\frac{\left(e_{3}-e_{1}\right)}{l_{F}} z_{\mathrm{K}}+e_{1} \text { and } y_{m}\left(z_{K}\right)=\frac{\left(e_{4}-e_{2}\right)}{l_{F}} z_{\mathrm{K}}+e_{2}
$$

The last term in the Reynolds equation, eqn. (1), expresses the contribution to the pressure generation due to the squeeze motion of the piston, which can also be determined by the piston shifting velocity $\dot{\mathbf{e}}=\left\{\dot{e}_{1}, \dot{e}_{2}, \dot{e}_{3}, \dot{e}_{4}\right\}$ and the transient squeeze film effect due to elastic surface deformation $\Delta \dot{\mathbf{h}}$ with the equation:

$$
\dot{h}\left(z_{\mathrm{K}}, \phi_{\mathrm{K}}\right)=-\dot{x}_{\mathrm{m}}\left(z_{\mathrm{K}}\right) \cdot \cos \phi_{\mathrm{K}}-\dot{y}_{\mathrm{m}}\left(z_{\mathrm{K}}\right) \cdot \sin \phi_{\mathrm{K}}+\Delta \dot{h}
$$

The transient squeeze film effect due to elastic surface deformation $\Delta \dot{h}$ is neglected in this study. The Reynolds equation is solved numerically dividing the fluid film range into a computing grid. The iterative coupling between micro motion of the rigid parts and Reynolds equation is realized according to the method developed by Wieczorek and Ivantysynova [5], based on a finite volume approach.

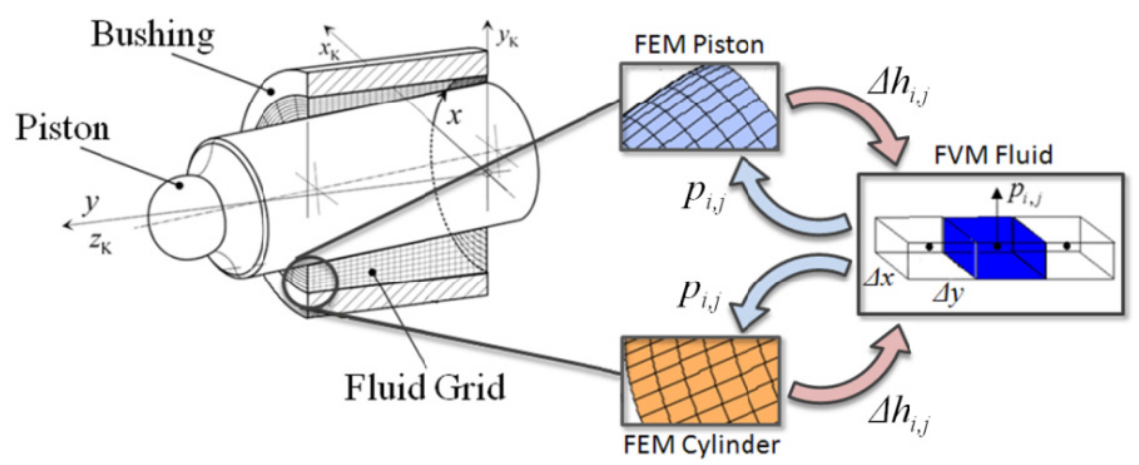

Figure 3: Gap fluid film computing grid coupled with finite element code.

Considering the fluid-structure interaction problem, the novelty of the model is represented by the use of a complete piston/cylinder built-in finite element tool, coupled with the gap flow finite volume model, used to accurately solve for the rigid bodies surface elastic deformation. The rigid body finite element code is coupled with the finite volume code for gap flow calculations, iteratively exchanging information on pressure field and surface deformation. Therefore, the elastic surface deformation calculation affects the gap pressure field and the piston micro movement. The new piston eccentricity position is calculated after integrating the piston shifting velocity. 
The surface elastic deformation problem does not represent the only aspect covered by the fully coupled model, in fact the solution of the Reynolds equation is also affected by the values of local dynamic fluid viscosity, $\mu$. Viscosity is strongly dependent on local temperature and pressure as described by Ivantysyn and Ivantysynova [6]:

$$
\mu=\mu_{0} \cdot \exp \left(\alpha_{p} \cdot p-k_{T} \cdot\left(T-T_{0}\right)\right)
$$

with $\mu_{0}$, the dynamic viscosity of the fluid at reference temperature, $T_{0}$. Therefore, to determine an accurate viscosity field, calculations on the heat transfer phenomena occurring in the gap are necessary. In particular, the change of local temperature in the gap is calculated by solving the energy equation, represented by eqn. (7).

$$
c_{P} \cdot \rho \cdot\left(\frac{\partial T}{\partial t}+\mathrm{v} \cdot \operatorname{grad} T\right)=\lambda \cdot \operatorname{div}(\operatorname{grad} T)+\mu \cdot \Phi_{\mathrm{D}}(\mathrm{v})
$$

The term on the left side of the equation describes the heat convection and the first term on the right side of the equation describes the heat conduction. The energy dissipation due to viscous fluid flow is represented by $\Phi_{D}$. The assumption of steady state conditions is made, thus $\partial T / \partial t=0$. Considering the unwrapped cylindrical gap on a Cartesian coordinates system, the energy equation is eqn. (8), following the method proposed by [7].

$$
c_{P}\left(v_{\hat{x}} \frac{\partial T}{\partial \hat{x}}+v_{\hat{y}} \frac{\partial T}{\partial \hat{y}}\right)=\frac{1}{\rho}\left[\frac{\partial}{\partial \hat{x}}\left(\lambda \frac{\partial T}{\partial \hat{x}}\right)+\frac{\partial}{\partial \hat{y}}\left(\lambda \frac{\partial T}{\partial \hat{x}}\right)+\frac{\partial}{\partial \hat{z}}\left(\lambda \frac{\partial T}{\partial \hat{z}}\right)\right]+\frac{\mu}{\rho} \Phi_{D}
$$

After solving the Reynolds and energy equations, the gap pressure and temperature fields are calculated; the fluid viscosity is updated for each element in the three-dimensional grid using eqn. (6). The dependency of density on pressure and temperature is as well considered and given by:

$$
\rho(p, T)=\rho_{0} \cdot\left(1+\beta_{p} \cdot\left(p-p_{0}\right)-\beta_{T} \cdot\left(T-T_{0}\right)\right)
$$

where $\beta_{p}$ represents the compressibility coefficient, $\beta_{T}$ the volume expansion coefficient and $\rho_{0}$, the reference oil density. Based on the film thickness local temperature distribution, the non-isothermal gap flow model calculates energy dissipation in the gap, heat conduction and heat convection of the fluid.

This information is exchanged with a finite volume model of the piston and cylinder bodies that allows calculating rigid bodies surface temperatures at the end of each simulated revolution. Instead of assuming constant boundary temperature conditions, the simulated surface temperatures are used as a boundary for non-isothermal gap flow calculations in the next revolution. The algorithm of the program can be better explained referring to fig. 4 . The core of the software, completely written in $\mathrm{C}++$, is represented by the Reynolds and Energy equation. The most inner loop solves for the pressure and temperatures field in the lubricating gap using a finite volume discretization. The gap flow equations are iteratively solved updating the fluid properties (viscosity and density) until convergence of the fields is reached. Based on the simulated pressure field the load carrying capability of the gap is determined together with the calculation of the external forces acting on the piston. An outer loop based on a Newton Iteration scheme, varies the piston shifting velocity to achieve a load 
balanced condition. For this reason the gap is self adjusted based on the external loads, which are oscillating over one shaft revolution. Furthermore, based on the temperature distribution inside the gap, the heat fluxes due to conduction, convection and energy dissipation to the fluid film surrounding the solid parts are determined at each time step. Once the load is balanced, the contribution of the solid parts surface elastic deformation to the micro-motion of the piston is considered, solving for the simulated pressure field the surface elastic deformation of the solid parts using a built in finite element model. The updated film thickness due to the surface elastic deformation is used to determine a new balanced condition and a pressure convergence loop, ensure that an adequate istantaneous pressure field is determined. At the end of the revolution, the total calculated heat fluxes are used to determine the piston and cylinder surface temperatures, using finite volume models of the solid parts. These temperatures are than used in the next revolution as boundary conditions for non-isothermal gap flow calculations. The most outer loop continues to iterate until a stable surface temperature is reached. The finite element model for surface elastic deformation and the finite volume model for surface temperature calculation will be described in the following section.

\section{Piston/cylinder deformation and heat transfer model}

The piston/cylinder numerical finite element model has the objective of determining accurately the gap surface deformation for given pressure field. A discretization of the model is thus necessary to evaluate with a high level of accuracy the response of the solid part to pressure compressive stresses. The developed finite element meshing and solver tool follow the structure of the model described in [8] for the slipper/swashplate interface, introducing few radical changes in order to accommodate the different type of lubricating gap. As represented in fig. 5, the challenge in the solution of this problem is represented by the piston motion, which continuously changes mesh characteristics over time. An adaptive meshing approach has been developed, where the mesh size is changed according to piston position, in order to avoid interpolation between the fluid grid and the solid grids.

Furthermore, the mesh generator informs the solver about the constraint conditions. In particular, the cylinder is assumed to be constrained on the external surface, while the piston is assumed to be in a balanced position and is constrained with respect to its axis.

The piston/cylinder heat transfer model allows determining the surface temperatures of the rigid parts, which serve as new boundary condition for the gap flow non-isothermal model. The calculation allows a more accurate energy dissipation prediction. The heat transfer model is based on a finite volume discretization of the piston/cylinder assembly, using the method proposed by Ivantysynova et al. [9] and Jouini et al. [10]. The novelty is the full coupling of the heat transfer model with the non-isothermal gap flow model, solving the challenge represented by piston motion. An interpolation scheme, coupled with the multi-body dynamic part of the simulation code, assigns at each time step the 


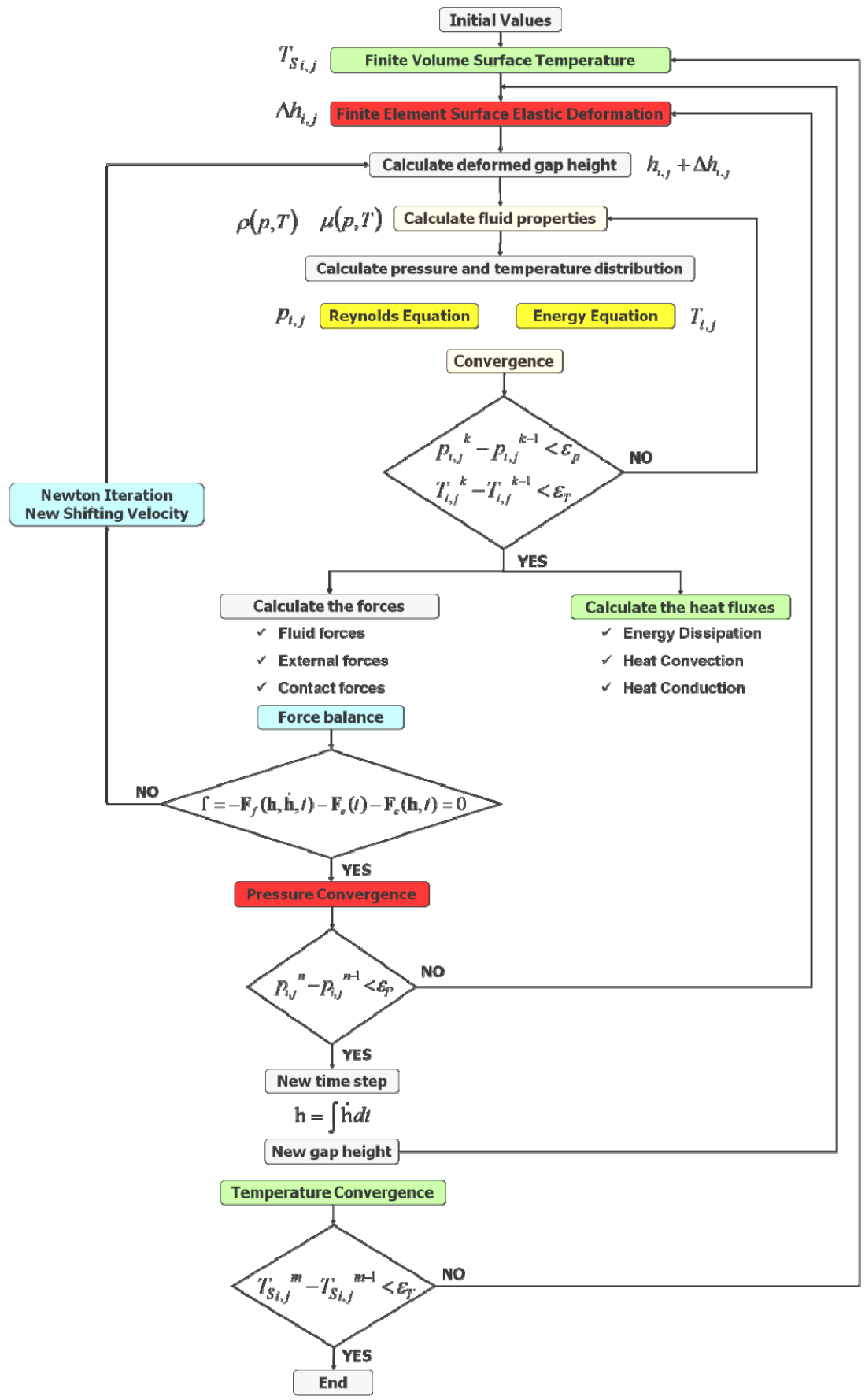

Figure 4: Flow chart representing the fully-coupled algorithm. 


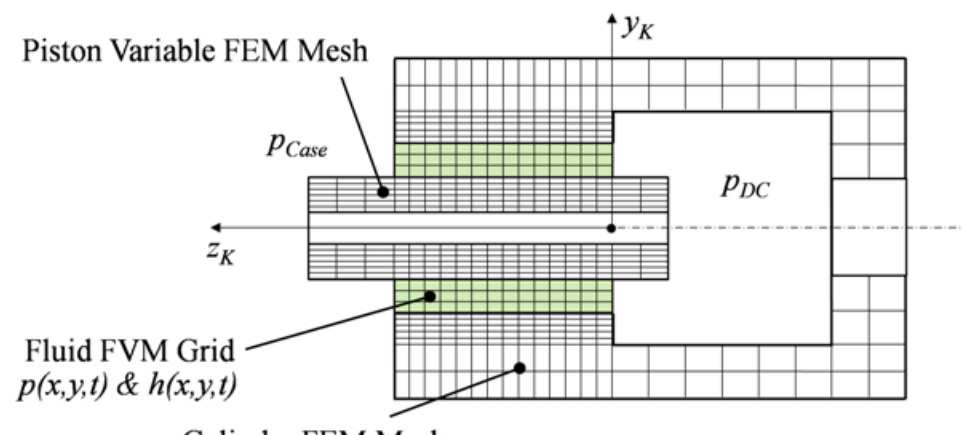

Cylinder FEM Mesh

Figure 5: $\quad$ Piston/cylinder finite element mesh.

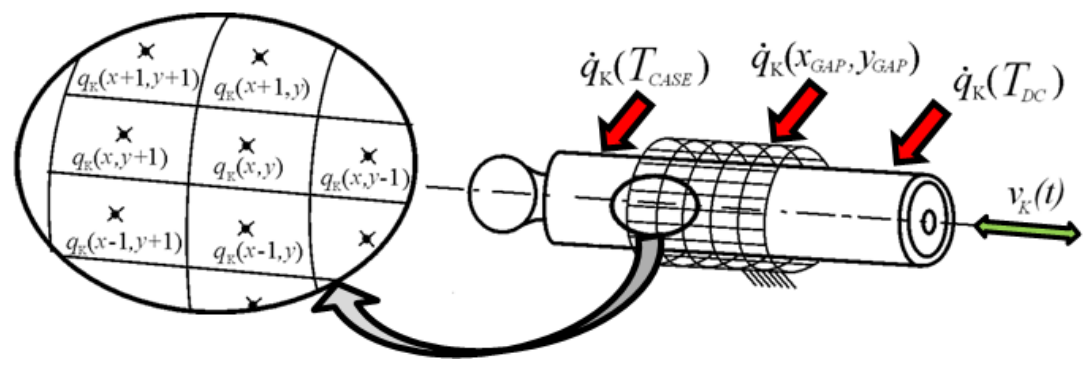

Figure 6: Variable heat transfer condition due to piston motion.

correct heat flux boundary $\dot{q}_{K}$ to the solid parts surfaces, as represented in fig. 6. The heat transfer model determines the surface temperatures taking into consideration the heat flux generated in the lubricating gap, calculated by the non-isothermal gap flow model, and the heat fluxes given by the other boundary condition on the parts. In particular, the heat transfer through the solid parts (piston and cylinder) due to the oil in the displacement chamber, (DC), and the leakage oil in the case are considered as boundaries.

\section{Numerical results and measurements}

The new model has been tested by simulating the gap flow conditions between piston and cylinder for a special design test pump. The pump has only one piston/cylinder assembly to allow enough space for implementing pressure and temperature sensors around the piston. The test pump allows measurements of pressure fields in the gap lubricant and the cylinder surface temperature [11]. In particular, 9 temperature sensors and 9 pressure sensors are mounted with varying circumference and gap length around the cylinder, as shown in fig. 7.

A locking device permits fixing the block in 180 different angular positions to measure the pressure and temperature field based on 1620 measurements points, see fig. 8 . 

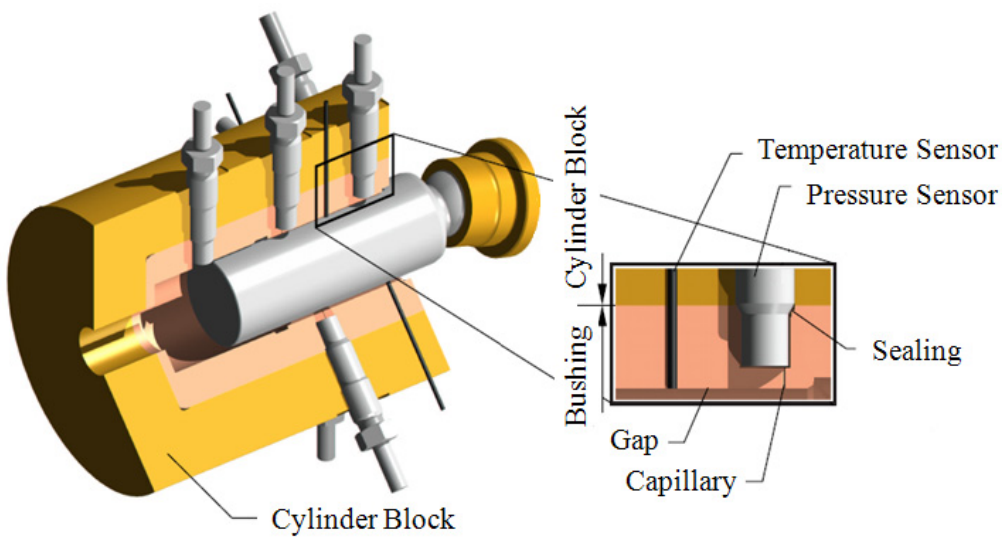

Figure 7: Cylinder block of test pump with pressure and temperature sensors around the cylinder.

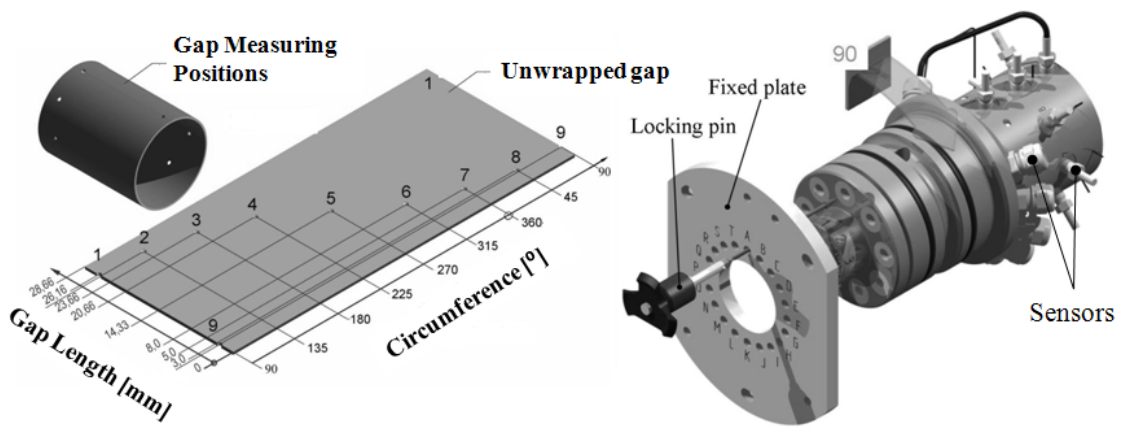

Figure 8: Measurement points on cylinder surface and locking device system.

The numerical results and measurements from a single operating condition, tab. 1, are presented in this paper.

Table 1: $\quad$ Operating conditions.

\begin{tabular}{|l|c|c|}
\hline Differential Pressure & 225 & bar \\
\hline Angular Speed & 1000 & $\mathrm{rpm}$ \\
\hline Case Temperature & 57.5 & ${ }^{\circ} \mathrm{C}$ \\
\hline Temperature at High Pressure Port & 48 & ${ }^{\circ} \mathrm{C}$ \\
\hline Temperature at Low Pressure Port & 43 & ${ }^{\circ} \mathrm{C}$ \\
\hline
\end{tabular}

Fig. 9 shows the comparison between the simulated and measured cylinder surface temperature. The model allows also the calculation of piston surface temperature. Numerical results on the gap converged pressure field and corresponding piston surface elastic deformation are shown in fig. 10 , for a shaft 

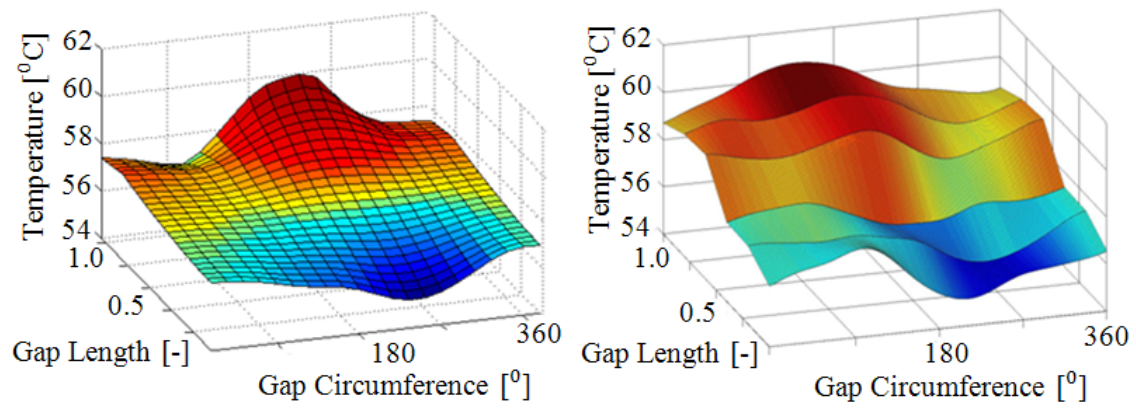

Figure 9: $\quad$ Simulated cylinder surface temperature (left) versus measured (right).
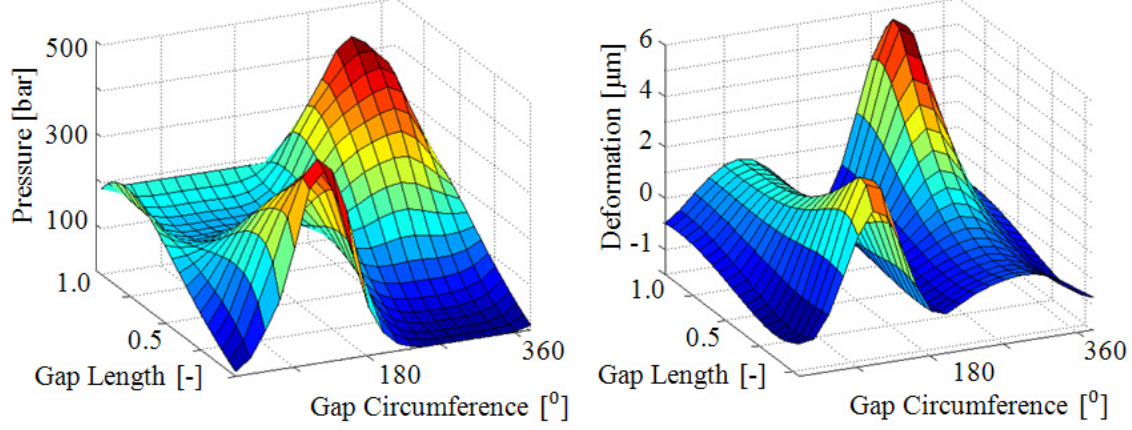

Figure 10: Gap pressure field and corresponding piston elastic deformation.
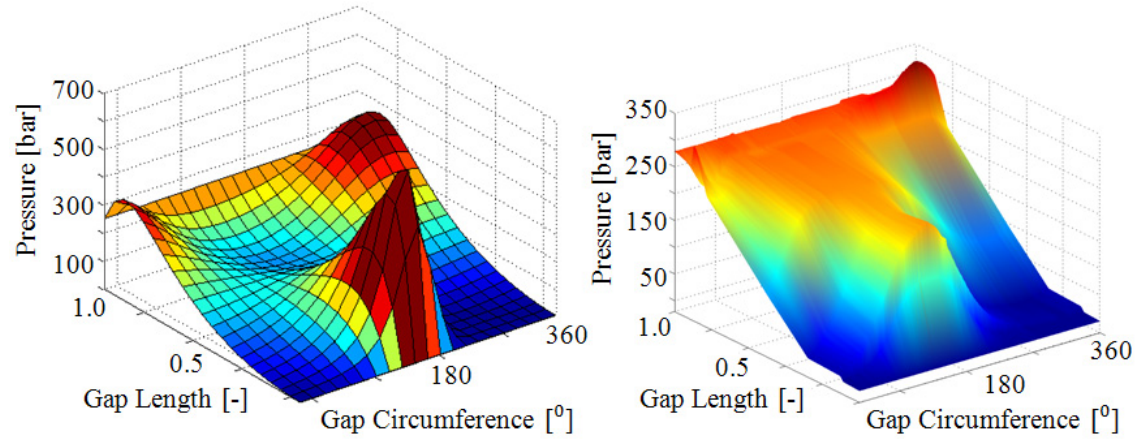

Figure 11: $\quad$ Simulated gap pressure field (left) versus measured (right). 
angular position of $14^{\circ}$. The cylinder surface elastic deformation is also considered in the calculations, even if not shown.

Furthermore, a comparison between the gap simulated and the measured pressure field for a shaft angle of $135^{\circ}$ is shown in fig. 11 .

The finite number of measurements points defining the measurement grid around the gap surface does not allow capturing the highest pressure peaks.

\section{Conclusions}

A fully coupled fluid-structure-thermal multi-body dynamics simulation model for the piston/cylinder interface of axial piston machines has been presented. The model considers the detailed physics of various phenomena, coupling nonisothermal gap flow with elastic surface deformation of the solid parts, heat transfer through the solid parts and their impact on micro-motion. Numerical results are shown for cylinder surface temperature distribution, gap pressure field and surface deformation. The calculated temperature and pressure fields are compared with measurements. It is shown how the model allows predicting the complex behavior of the piston/cylinder lubricating gap. In the future, the fully coupled model will be extended in the same fashion to the other two lubricating gaps of the axial piston machine, the cylinder block/valve plate and the slipper/swash plate interface.

\section{List of Notations}

$\begin{array}{lll}h(i, j) & \text { Gap height of grid (i,j) } & \mathrm{m} \\ \dot{h} & \text { Piston shifting velocity } & \mathrm{m} / \mathrm{s} \\ \Delta h & \text { Gap nodal deformation } & \mathrm{m} \\ e_{1}, e_{2}, e_{3}, e_{4} & \text { Piston eccentricities } & \mathrm{m} \\ p & \text { Pressure } & \mathrm{Pa} \\ t & \text { Time } & \mathrm{s} \\ T & \text { Temperature } & { }^{\circ} \mathrm{C} \\ T_{0} & \text { Reference temperature } & { }^{\circ} \mathrm{C} \\ v_{x} & \text { Fluid velocity circumferential direction } & \mathrm{m} / \mathrm{s} \\ v_{y} & \text { Fluid velocity axial direction } & \mathrm{m} / \mathrm{s} \\ z_{K} & \text { Piston axis coordinate } & \mathrm{m} \\ R_{K} & \text { Piston radius } & \mathrm{m} \\ \phi_{K} & \text { Angular position for gap definition } & \mathrm{rad} \\ l_{F} & \text { Gap length } & \mathrm{m} \\ \hat{x}, \hat{y}, \hat{z} & \text { Unwrapped Cartesian coordinates } & \mathrm{m} \\ \varphi & \text { Shaft angular rotation } & \mathrm{rad} \\ \rho & \text { Fluid density } & \mathrm{kg} / \mathrm{m}^{3} \\ \rho_{0} & \text { Fluid reference density } & \mathrm{kg} / \mathrm{m}^{3} \\ \mu & \text { Fluid viscosity } & \mathrm{Pa} \cdot \mathrm{s} \\ \mu_{0} & \text { Fluid reference viscosity } & \mathrm{Pa} \cdot \mathrm{s} \\ \alpha_{P} & \text { Viscosity-pressure coefficient } & \mathrm{Pa}\end{array}$




$\begin{array}{lll}k_{T} & \text { Viscosity-temperature coefficient } & \mathrm{K}^{-1} \\ c_{P} & \text { Fluid specific heat capacity } & \mathrm{J} /(\mathrm{kgK}) \\ \Phi_{D} & \text { Mechanical dissipation function } & - \\ \lambda & \text { Thermal conductivity } & \mathrm{W} /(\mathrm{mK})\end{array}$

\section{References}

[1] Tanaka, K., Kyogoku, K. \& Nakahara, T., Lubrication characteristics on sliding surfaces between piston and cylinder in a piston pump and motor (Effects of running-in, profile of piston top and stiffness). JSME International Journal, Series C (Mechanical Systems, Machine Elements and Manufacturing), 42(4), pp. 1031-1040, 1999.

[2] Fatemi, A., Wohlers, A. \& Murrenhoff, H., Simulation of Elastohydrodynamic Contact between Piston and Cylinder in Axial Piston Pumps. Proc. of the $6^{\text {th }}$ International Fluid Power Conference: Dresden, pp. 539-552, 2008.

[3] Dowd, J. R., \& Barwell, F. T., Tribological interaction between piston and cylinder of a model high pressure pump. Transactions ASLE, 18, pp. 21-30, 1974.

[4] Fang, Y., \& Shirakashi, M., Mixed lubrication characteristics between piston and cylinder in hydraulic piston pump-motor. Journal of Tribology, Trans. ASME, 117, pp. 80-85, 1995.

[5] Wieczorek, U. \& Ivantysynova, M., Computer Aided Optimization of Bearing and Sealing Gaps in Hydrostatic Machines - The Simulation Tool CASPAR, International Journal of Fluid Power, 3(1), pp. 7-20, 2002.

[6] Ivantysyn, J. \& Ivantysynova, M., Hydrostatic Pumps and Motors, Academic Books International, New Delhi, 2001.

[7] Ivantysynova, M., Temperaturfeld im Schmierspalt zwischen Kolben und Zylinder einer Axialkolbenmaschine. Maschinenbautechnik 34, pp. 532535, 1985.

[8] Pelosi, M. \& Ivantysynova, M., A New Fluid Structure Interaction Model for the Slipper-Swashplate Interface. Proc. of the 5th FPNI PhD Symposium, Fluid Power Net International: Cracow, pp. 219-236, 2008.

[9] Ivantysynova, M., Huang, C. \& Japing, A, Determination of gap surface temperature distribution in axial piston machines. Proc. of the 2006 ASME International Mechanical Engineering Congress, IMECE2006-15249: Chicago, 2006.

[10] Jouini, N., \& Ivantysynova, M., Valve Plate Temperature Prediction in Axial Piston Machines. Proc. of the $5^{\text {th }}$ FPNI PhD Symposium, eds. Fluid Power Net International: Cracow, pp. 95-110, 2008.

[11] Ivantysynova, M., Huang, C. \& Behr, R., Measurements of elastohydrodynamic pressure field in the gap between piston and cylinder. Proc. of the 2005 Power Transmission and Motion Control, eds. D.N. Johnston, C.R. Burrows \& K.A. Edge: Bath, pp. 451-465, 2005. 